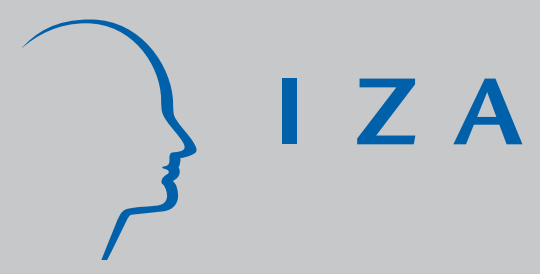

IZADP No. 2556

Product Market Integration and Labour Markets: Aggregate Gains at the Cost of More Inequality?

Torben M. Andersen

Allan Sørensen

J anuary 2007 


\title{
Product Market Integration and Labour Markets: Aggregate Gains at the Cost of More Inequality?
}

\author{
Torben M. Andersen \\ University of Aarhus, \\ CEPR, EPRU and IZA \\ Allan Sørensen \\ University of Aarhus
}

\section{Discussion Paper No. 2556 \\ January 2007}

IZA
P.O. Box 7240
53072 Bonn
Germany

\author{
Phone: +49-228-3894-0 \\ Fax: +49-228-3894-180 \\ E-mail: iza@iza.org
}

\begin{abstract}
Any opinions expressed here are those of the author(s) and not those of the institute. Research disseminated by IZA may include views on policy, but the institute itself takes no institutional policy positions.

The Institute for the Study of Labor (IZA) in Bonn is a local and virtual international research center and a place of communication between science, politics and business. IZA is an independent nonprofit company supported by Deutsche Post World Net. The center is associated with the University of Bonn and offers a stimulating research environment through its research networks, research support, and visitors and doctoral programs. IZA engages in (i) original and internationally competitive research in all fields of labor economics, (ii) development of policy concepts, and (iii) dissemination of research results and concepts to the interested public.
\end{abstract}

IZA Discussion Papers often represent preliminary work and are circulated to encourage discussion. Citation of such a paper should account for its provisional character. A revised version may be available directly from the author. 


\section{ABSTRACT}

\section{Product Market Integration and Labour Markets: Aggregate Gains at the Cost of More Inequality?*}

Important labour market consequences of globalization may arise via product market integration which affects the room for wage negotiations and generates job creation and destruction through structural changes. We find in a Ricardian trade model that aggregate increases in wages and employment may conceal important differences across sectors/groups driven by a different balance between "protection" and "specialization" rents. In particular, wage inequality tends to be U-shaped, at first decreasing and then increasing in the process of product market integration. Consequently, there are gains in both the efficiency and the equity dimension until the level of integration reaches a certain level at which a trade-off arises.

JEL Classification: F15, F16, J39, J50, J63

Keywords: trade frictions, relative productivity, rent sharing, job turnover, inequality

Corresponding author:

Torben M. Andersen

Department of Economics

University of Aarhus

Universitetsparken

8000 Aarhus C

Denmark

E-mail: tandersen@econ.au.dk

\footnotetext{
Comments on earlier versions by participants at the workshops "Globalization - Implications for labour markets and welfare policies", "Inequality in the Labour Market", "2 ${ }^{\text {nd }}$ Danish International Economics Workshop", and "Income Distribution, Globalization and Economic Policy" as well as Morten Hviid, Kjell Erik Lommerud, Ulrik Nødgaard, Pascalis Raimondos-Møller, Bo Sandemann Rasmussen, Christian Schultz, and Valdemar Smith are gratefully acknowledged. We gratefully acknowledge support from the Danish Social Science Research Council.
} 


\section{Introduction}

The pros and cons of globalization are vividly debated, and the labour market consequences are among the most persistent concerns. How will wage and employment prospects be affected? Who will be the winners and who will be the losers? Will more inequality inevitably follow?

The standard response of economists is to point to aggregate welfare gains accruing from further integration, but this answer is not very convincing to individuals facing the consequences of structural changes and increasing uncertainty wrt. future job and wage prospects. A point which cannot be neglected since the gains from further international integration are intimately related to structural changes. Some activities contract and others expand in a process where production allocation across countries becomes more closely aligned to comparative advantages. This process inevitably has both winners and losers via job destruction and creation as well as changing wage prospects.

The term globalization captures many aspects and processes, and we here focus on product market integration induced by political and technological changes causing a decrease in frictions and barriers for market entry and penetration. From this perspective, the effects of globalization can be summarized as "unbundling" (Baldwin(2006)). International integration has reduced the importance of geographical proximity first between consumers and producers (unbundling type I) and more recently between suppliers of intermediaries for final goods production (unbundling type II). The main effect of this is that it makes relocation of production (final commodities and intermediaries alike) across distance and borders easier, and thereby it causes more specialization in production. A crucial effect of this is that some non-tradeable activities become tradeables.

A useful way to think about the labour market consequences of product market integration is to focus on the scope for rent extracting between the firm and its employees. Basically, two factors can create rents to be shared in wage negotiations, namely rents created by limited market entry (in the following termed protection rents) and rents created by having higher productivity than competitors (specialization rents) ${ }^{1}$. Globalization will in a critical way change the balance between these two types of rents since it implies both easier market entry and further specialization.

Market integration causes some former non-tradeables to become either importables or exportables and this, in turn, affects the scope for appropriating the two types of rents outlined above. In a fairly closed economy, most activities are non-tradeables since domestic markets are protected from penetration by foreign firms, and this improves the scope for rent extraction (protection rents). Obviously integration erodes the scope for extracting such rents. In more integrated economies, less efficient domestic production is driven out of business by more efficient foreign production, and vice versa, more efficient domestic pro-

\footnotetext{
${ }^{1}$ In an imperfectly competitive market with homogenous goods, rents are created to the extent that the firm can produce at costs lower than any competitor. The latter determines the "threat point" in terms of pricing, and this creates a rent for the lowest cost firm.
} 
duction can drive less efficient foreign production out of business. This implies that production is better allocated across countries according to productivities (comparative advantages) which, in turn, implies specialization and improved scope for extracting specialization rents.

The aim of this paper is to study these mechanisms in a setting integrating the trade and labour market aspects of product market integration (trade frictions, endogenous trade structure, specialization etc.). To focus sharply on how product markets affect labour markets via the scope for rent extraction, we stylize the model so as to clarify the role of rent creation and sharing.

The model presented in this paper embed in its general equilibrium structure mechanisms which have been studied in mainly partial analysis of the labour market consequences of product market integration. The focus of this literature is how the room for wage bargaining is affected by product market integration creating both import threats and export opportunities. Most of the literature takes its outset in either models of reciprocal dumping (see e.g. Naylor (2000)) or a Ricardian setting (see below) ${ }^{2}$. We use the latter approach here since it allows a straightforward modelling of relocation and specialization of production capturing important aspects of the globalization process ${ }^{3}$ and since it can readily be incorporated into a general equilibrium setting.

The paper is related to a voluminous labour market literature on wage determination and wage inequality. A large number of studies have analysed how wage setting is affected by the trade position of firms, and have pointed to import threats exerting a downward pressure and export opportunities exerting an upward effect on wage setting ${ }^{4}$. Recent evidence points to more polarization in labour markets (see e.g. Autor, Katz and Kearney (2006)) in the sense of unequal prospects for job creation and increasing dispersion in wages (at the

\footnotetext{
${ }^{2}$ The two approaches share the feature that frictions create some barrier for trade. In the reciprocal dumping model (see Brander (1981)), firms enter foreign markets (Cournot competition) to obtain a share of the product market rents. A Ricardian trade model is driven by differences in comparative advantages affecting the prices at which domestic and foreign firms can offer the goods (Bertrand competition). The different strategic assumptions are most important when domestic and foreign commodities are perfect substitutes since twoway trade then cannot arise under Bertrand competition (no capacity constraints). Hence, the two approaches cannot readily be merged. Gürtzen (2002) presents a version with Bertrand competition where domestic and foreign commodities are not perfect substitutes thus allowing for two-way trade. See also Andersen and Sørensen (2006a). In this paper, we maintain the assumption of perfect substitution and Bertrand competition, but by the sectoral structure and the distribution of productivities (comparative advantages), we ensure that there are importables, exportables and non-tradeables sectors.

${ }^{3}$ Recent empirical work also attributes a central role to specialization and comparative advantages as driving forces for the growth in trade (see e.g. Davis and Weinstein (2002) and Yi (2003))

${ }^{4}$ Bernard and Jensen $(1999,2001)$ and Bernard et al. (2003) find that exporting firms tend to have higher productivity and pay higher wages, with the causality running from productivity to exports. Interestingly, they also find that export tends to drive out less productive firms and induce a reallocation of production to more efficient firms. Schank, Schnabel and Wagner (2004) list 18 empirical studies using data from 20 countries, supporting that exporting firms tend to pay higher wages. Empirical studies have also found that import penetration tends to lower wages (see e.g. Boulhol et al.(2006), Revenga (1992), Nicoletti et al. (2001) and Jean and Nicoletti (2002)).
} 
top end of the distribution). An interesting point is that globalization implies that changes in labour market positions are not monotonously related to education or skills, but rather to the extent to which activities can be unbundled (Blinder (2005)). This stresses the importance of understanding how product market integration affects the room for wage setting and thus rents for various groups in the labour market. For this reason, the model is set-up to highlight rent creation and sharing. While going to the extreme, this allows a sharp focus on an important mechanism released by globalization. Obviously, other aspects are of importance for labour markets in general and wage setting in particular. However, the mechanisms highlighted here would be present also in more general formulations of the labour market and therefore it is useful to clarify the specific role of this key mechanism.

Since the effects of globalization on the non-tradeable sector are important and visible channels through which the unbundling mechanism works, it is important to be careful about the specification of non-tradeable activities. One important distinction is whether activities are non-traded because of frictions or due to the nature of the activity. Blinder (2005) made a distinction between personal and impersonal services to highlight that certain activities are of such a nature that they cannot be traded (personal services e.g. taxi drivers, health care) while others can be traded if the explicit and implicit costs of doing so are not too large relative to comparative advantages. To capture this, we separate the economy in two parts - the (potential) globalized ( $G$-sector) and the home part $(H \text {-sector })^{5,6}$. For the globalized part, we use a Ricardian framework with trade-frictions (see e.g. Dornbusch, Fischer and Samuelson (1977)) allowing an endogenous determination of the trade structure (non-tradeables, exportables, importables) and specialization, and thus how this is affected by further globalization. The home-sector produces goods which are of such a nature that they are non-tradeables.

We show that further integration creates both winners and losers. Evaluated in terms of wage premia (wages in excess of the default wage), some groups may find themselves in a position with a sharp drop in the wage premium (loss of protection rents) or even the possibility of being driven out of jobs (closure due to relocation of production from domestic to foreign production units) while, at the same time, others have improved possibilities due to a favourable comparative position (gain of specialization rent).

A major finding of the paper is that integration affects both the absolute and the relative importance of protection rents and specialization rents in a systematic way so as to produce a U-shaped relation between integration/openness and wage inequality. That is, in a process of integration, wage dispersion will at first decrease due to a decline in the importance of protection rents, and later wage inequality will increase due to an increase in the relative importance of specialization rents. The precise form of the $U$-shaped relation depends, among

\footnotetext{
${ }^{5}$ Essentially, we assume infinite trade frictions for some activities (H-sector) and finite identical costs for others (G-sector). A more general formulation would allow for different levels of trade frictions across various activities.

${ }^{6}$ A similar decomposition is made in Atkinson (2006) in a Heckscher-Ohlin model.
} 
other things, on the similarity of the countries (in terms of productivities and thus the distribution of comparative advantages, cf. below). If the integrating countries are not too similar, the "right leg" of the $U$ dominates (integration tending to increase inequality) since the specialization effect is large. Oppositely, the "left leg" dominates (integration tending to decrease inequality) if countries are sufficiently similar in which case the protection effect is dominating.

Due to a positive spill-over effect from higher activity, the wage in sectors completely shielded from international integration (the home sectors) grows faster than the average wage in the higher paying globalized sectors exposed to international competition ${ }^{7}$, and since the former is a low wage group, this affects the distribution of wages critically. An interesting corollary of this is that the workers in the home sector always are among the winners from further integration.

The main findings can be interpreted in the efficiency-equity space for the economy with efficiency measured by the mean income and equity by the standard deviation of income. At first, lowering of trade frictions causes gains in both the efficiency and equity dimension, but at a certain level of integration, a trade-off arises in the sense that further efficiency gains are achieved at the costs of rising inequality. Hence, product market integration does not necessarily cause a worsening of the equity-efficiency trade-off. Integration among less similar countries is more likely to induce a efficiency-equity trade-off than integration among more similar countries.

Employment is affected by both a general and a specific component. The general component is an aggregate demand effect arising via the gains from trade which, in turn, via an income effect tends to increase demand for all types of goods. The sector or good specific component is more complicated and related to the relocation of production and trade patterns of the particular good. There is job destruction among former non-tradeable sectors being driven out of business by penetrating imports, and job creation for firms penetrating into the foreign market as well as for firms lowering prices to curtail the competitive pressure from foreign firms. Gross flows in the labour market in the form of job destruction and creation are therefore affected by the structural changes induced by further integration. However, overall job creation exceeds job destruction in the globalized sectors which therefore have an increasing employment level.

The rest of the paper is organized as follows: Section 2 develops the general equilibrium model and details the interaction between price and wage formation and product market integration. Section 3 presents the main results on the effects of product market integration on wage inequality as well as on aggregate wages and employment. Section 4 concludes and briefly discusses possible extensions.

\footnotetext{
${ }^{7}$ Note that the model has full employment.
} 


\section{The Model}

For simplicity, we consider a two-country setting (foreign variables are denoted by $*$ ). The countries are assumed to be completely identical (symmetric structure) except that productivity in producing a given good may differ, cf. below. This assumption highlights the point that the results are not driven by aggregate differences in factor endowments, and it allows us to focus on the process of market penetration and entry (for a further discussion, see Section 3).

Each economy is composed of two parts, one which is not directly affected by product market integration (the home part), and another which is directly affected by product market integration (the globalized part). This decomposition allows an analysis of two dimensions of reallocation induced by product market integration, namely between the two parts of the economy and between firms/sectors in the globalized part. In the globalized part of the economy, there is a continuum of sectors and goods. Each global good is consumed and can in principle be produced in either country. It is endogenous whether a given global good turns out to be produced only at home (an exportable), only abroad (an importable) or in both countries (a non-tradeable).

Trade involves various frictions in the form of explicit or implicit trade costs. Assume that the trade frictions can be captured by Samuelson's iceberg costs (see e.g. Dornbusch, Fischer and Samuelson (1977)). Hence, in order to deliver one output unit of type $i$ on the market abroad, one has to produce $1+z_{i}$ $(\geq 1)$ units. Trade frictions are assumed to be symmetric with respect to the direction of trade. Integration of product markets is interpreted as reductions in the $z_{i}$ 's. Specifically, we compare steady states for different levels of trade frictions, i.e. we do not consider the transitional adjustment from one steady state to another ${ }^{8}$. Finally, note that the model is real disregarding all financial aspects.

\subsection{Households}

The utility function of a representative household is given by ${ }^{9}$

$$
U=\frac{1}{\lambda^{\lambda}(1-\lambda)^{1-\lambda}} H^{1-\lambda} G^{\lambda}
$$

where $H$ is the consumption of home goods which are not under any circumstances traded, and $G$ is a consumption bundle of global commodities. It is assumed that households supply one unit of labour inelasticly and that labour is indivisible (disutility of work is thus constant and eliminated to simplify). The consumer price index is given by

$$
Q=P_{G}^{\lambda} P_{H}^{1-\lambda}
$$

\footnotetext{
${ }^{8}$ Although an analysis of the transitional paths is very important for evaluating the consequences of product market integration, it is beyond the scope of this paper.

${ }^{9}$ Profit income is distributed to households, and since preferences are homothetic, it follows that it is aggregate income that determines demand, and thus income/wealth distribution is of no importance.
} 
The consumption bundle of global goods is defined as

$$
G=\left(\int_{0}^{1} C_{j}^{\frac{\epsilon-1}{\epsilon}} d j\right)^{\frac{\epsilon}{\epsilon-1}}, \epsilon>1
$$

where $C_{j}$ is consumption of goods from sector $j$. Accordingly, we have the following demand functions

$$
C_{j}^{d}=\left(\frac{P_{j}}{P_{G}}\right)^{-\epsilon} \frac{\lambda I}{P_{G}} \quad \forall j \in[0,1]
$$

where $I$ is aggregate nominal income, $P_{j}$ is the price index for sector $j$, and $P_{G}$ is the price index of global goods defined as

$$
P_{G}=\left(\int_{0}^{1} P_{j}^{1-\epsilon} d j\right)^{\frac{1}{1-\epsilon}}
$$

For each sector $j$, there exists a continuum of goods $i \in[0,1]$ over which the agents have the following CES preferences ${ }^{10}$

$$
C_{j}=\left(\int_{0}^{1} C_{j i}^{\frac{\epsilon-1}{\epsilon}} d i\right)^{\frac{\epsilon}{\epsilon-1}} \quad \forall j \in[0,1]
$$

and accordingly, we have the following demand functions

$$
C_{j i}^{d}=\left(\frac{P_{j i}}{P_{j}}\right)^{-\epsilon}\left(\frac{P_{j}}{P_{G}}\right)^{-\epsilon} \frac{\lambda I}{P_{G}}=\left(\frac{P_{j i}}{P_{G}}\right)^{-\epsilon} \frac{\lambda I}{P_{G}} \quad \forall(i, j) \in[0,1] \times[0,1]
$$

and the price indices for each sector and for the entire globalized segment can be rewritten as

$$
\begin{aligned}
P_{j} & =\left(\int_{0}^{1} P_{j i}^{1-\epsilon} d i\right)^{\frac{1}{1-\epsilon}} \forall j \in[0,1] \\
P_{G} & =\left(\int_{0}^{1}\left(\int_{0}^{1} P_{j i}^{1-\epsilon} d i\right) d j\right)^{\frac{1}{1-\epsilon}}
\end{aligned}
$$

The nesting of sectors and commodities implies that commodities in a given industry/sector can be either non-traded or traded (exported or imported). The model can therefore account for intra-industrial trade. Lower trade frictions will in this case lead to unbundling of type I where the geographical proximity of consumers and producers is loosened.

\footnotetext{
${ }^{10}$ The elasticity of substitution is set to be the same between sectors and between products within sectors to simplify calculations. However, as all sectors are identical, we have in equilibrium that

$$
P_{j}=P_{G} \text { for all } j \in[0,1]
$$

and the assumption is without loss of generality.
} 
The model can also be given an alternative interpretation. Let $G$ be the final consumption good produced by various intermediaries $\left(C_{j}\right)$ according to the production function (1), see e.g. Yi (2003). Intermediaries are produced according to the production function (2) by use of various types of inputs $\left(C_{j i}\right)$. The inputs into the production of intermediaries can be thought of as (being produced by) various types of labour tasks ${ }^{11}$. In this interpretation, the model captures unbundling of type II where the geographical bundling of production is loosened.

Note that since sectors and subsectors are assumed symmetric, there is no loss in analysing only one sector, and therefore the $j$ subscript is dropped in the following to simplify notation ${ }^{12}$.

\subsection{Firms in the home part (the $H$ segment)}

The home part of the economy is assumed to be perfectly competitive. Firms produce homogenous goods specific to the home market in the sense that this commodity is not exposed to any potential foreign competition ${ }^{13}$. The representative firm has the following constant return to scale production function with labour as the only input

$$
Y_{H}=L_{H}
$$

and due to perfect competition, it must be the case that

$$
P_{H}=W
$$

where $W$ is the competitive market clearing wage, cf. below.

\subsection{Firms in the globalized part (the $G$ segment)}

Assume that for each good $i \in[0,1]$ there is one potential producer in each country, that is, we assume an international duopoly for each good. The production technique of the home firm potentially producing good $i$ is given by a constant returns to scale production function with labour as the only input

$$
Y_{i}=A_{i} L_{i}
$$

where $L_{i}$ is input of labour, and $A_{i}$ is the (exogenous) firm-specific productivity parameter (see e.g. Bernard et al. (2003) and Melitz (2003) for some recent trade models with exogenous heterogeneity in productivity across firms $)^{14}$. Note that $A_{i}$ can be interpreted as capturing different education, ability, or training

\footnotetext{
${ }^{11}$ Grossman and Rossi-Hansberg (2006a,b) introduce offshoring of tasks in a HeckscherOhlin framework allowing for a different change in trade frictions for skilled and unskilled labour.

${ }^{12}$ A natural extension of the model is to allow for heterogenous sectors which would imply inequality across groups.

${ }^{13}$ We basically assume that trade costs for goods produced in the home part are prohibitively high for export to take place for any degree of product market integration.

${ }^{14}$ In fact the product market formulation is a simplification of that in Bernard et al. (2003). We consider the special case with two countries and one potential producer in each country.
} 
levels of labour, reflecting different capital-labour ratios, or differences related to technological advances, learning etc.

Foreign production technology is similarly given as

$$
Y_{i}^{*}=A_{i}^{*} L_{i}^{*}
$$

where foreign productivity $A_{i}^{*}$ may differ from domestic productivity $A_{i}$ in producing commodity $i$ (see below).

Firms are in Bertrand competition (see below), and we denote the revenue and employment generated by a firm $R_{i}$ and $L_{i}$, respectively. We will assume the following timing of actions taken by firms in the $G$ segment: First, firms determine prices (market entry), then they hire labour, and finally wages are negotiated. ${ }^{15}$

\subsection{The labour market}

The question of inequality becomes of interest only if there are some labour market related differences/heterogeneities across workers. It is complicated and complex to explain these differences, which, among the many potential explanatory factors, include abilities, skills and experiences. For the present analysis, the key issue is the scope for appropriating some of the rents accrued by firms qua their position in the product market ${ }^{16}$. This situation can be modelled by a simple putty-clay structure in the sense that all workers are ex ante alike, but may differ in an ex-post sense depending on their job position. The puttyclay structure ensures that there is heterogeneity within the labour force, and therefore structural changes will affect different groups to different extents. The assumption is extreme in the sense of allowing complete ex-ante flexibility and no ex-post flexibility in job mobility across firms, but to a first approximation it captures the empirically relevant case of non-malleability of all types of jobs/workers.

The sectoral structure of the economy implies that workers are either working in an $H$ or a $G$ firm. All workers are ex-ante alike and therefore have equal capabilities and opportunities of working in a given firm. For jobs in a $G$ firm, we assume the above-mentioned putty-clay structure. The $H$-sector has a residual role - if unable to find a job in a $G$ firm, one can always turn to the (lower paying) $H$-market. One can think of the $H$ segment as a service sector

\footnotetext{
${ }^{15}$ The assumption about the timing may seem rather strict and seems only to be reasonable when the firm engages in long term product market contracts. However, another interpretation is that wage contracts can be renegotiated, whereas this is not the case for product market contracts, or that it is easier to renrgotiate the former than the latter. Further, it should be noted that the same results would be obtained in a setting where the firm freely can determine the group of workers with whom to enter into an "efficient bargaining" over the wage, prices and thus employment. The assumption that the firm is able to replace workers in the group negotiating with the firm corresponds to assuming away insider-outsider issues.

${ }^{16}$ It is well-known that human capital variables can only account for a small part of wage inequality (for a recent discussion see Lemieux (2005)). The present formulation can be seen as an attempt to analyse the role of other factors than human capital for wage inequality.
} 
("taxi drivers") or home production in which it is always possible to find a job. In this sense, there is always full employment.

Turning to the specifics, the $H$ labour market is competitive. Labour supply equals the number of households (normalized to unity), i.e. the clearing condition for the labour market reads

$$
1=L_{H}^{d}+L_{G}^{d}
$$

where $L_{H}^{d}$ is labour demand in the $H$ segment, and $L_{G}^{d}$ is total labour demand from firms in the $G$ segment (see below). The market clearing wage for the $H$ sector is as noted $W$.

The structure of the $G$-labour market is the following: ex ante identical workers (putty) apply for jobs (no job search costs), firms decide on employment and make hirings at random among the applicants, and subsequently wages are negotiated with workers matched to the firm (clay). The putty-clay structure creates a lock-in situation allowing workers to appropriate some of the rent generated in the product market. Note two implications of this structure. First, wages in any $G$ firm cannot be below the wage in the $H$ market $(W)$ since all workers can turn to this market on the spot. Hence, this market can also be seen as a simple way of introducing a minimum wage effect in wage setting ${ }^{17}$. Second, job search is trivial in the sense that all workers ex ante would apply for jobs in any $G$ firm, and the allocation of workers across firms is random.

We shall consider wage setting for a given labour force in a $G$-firm and later turn to a determination of the labour force and the pricing decision. Utilizing the Nash bargaining model, we find that the bargaining outcome is given as the solution to

$$
\max _{W_{i} \geq W}\left[R_{i}-W_{i} L_{i}\right]^{1-\alpha}\left[L_{i}\left(W_{i}-W\right)\right]^{\alpha}
$$

where $R_{i}$ is revenue, $L_{i}$ is employment, $W_{i}$ is the wage, and $\alpha \in[0,1]$ is the relative bargaining power of the workers (see e.g. Moene and Wallerstein (1993)). The fall-back positions are determined by what happens in the case of no agreement. We assume that no production will take place and workers will find a job in the competitive $H$ segment. Thus, the fall-back positions are zero and $W$ for firms and workers, respectively. Solving the bargaining problem yields the following wage equation

$$
W_{i}=\alpha \frac{R_{i}}{L_{i}}+(1-\alpha) W
$$

which implies revenue sharing in the sense that the wage is determined as a weighted average of revenue per worker (weighted by the bargaining power of unions) and the competitive wage (weighted by the bargaining power of firms). It follows that the market position of firms, including its trade position, may affect wage formation.

\footnotetext{
${ }^{17}$ Alternatively, but more complicated, this could be done via some unemployment benefit scheme.
} 
The reduced form profit of the firm is given by

$$
\Pi_{i}=R_{i}-W_{i} L_{i}=(1-\alpha)\left(R_{i}-W L_{i}\right)
$$

Thus, the relevant marginal labour cost for a firm maximizing the reduced form profit is given by the competitive wage $W$. The intuition behind this result is that the coalition consisting of the firm and the workers share the surplus (the product market rents) gained from agreement in fixed proportions. Thus, maximizing profits are equivalent to maximizing the total surplus from agreement which is given by

$$
S=R_{i}-W_{i} L_{i}+L_{i}\left(W_{i}-W\right)=R_{i}-W L_{i}
$$

where the (opportunity) labour costs $W L_{i}$ are determined by the fact that each worker in case of no agreement would earn $W$ on the competitive labour market. To put it differently, firm specific wages only play a role in sharing the rents between workers and the firm, but do not affect the price and thus the production decision. ${ }^{18}$ Since an agreement will only be reached when there is a positive surplus from agreement, it follows using (8) and (10) that the lowest wage paid in the $G$ segment equals the competitive wage. Finally, note that the putty-clay structure prevents any attempts at ex-post underbidding across workers ${ }^{19}$.

\subsection{Directions of trade and prices}

Under the assumption of Bertrand competition, it is fairly easy to determine the direction of trade, i.e. which of the global commodities are produced in the home country and in the foreign country. As noted above, the relevant marginal cost of labour is the competitive wage, $W$, thus, the relevant marginal cost of production is

$$
M C_{i}=\frac{W}{A_{i}} \equiv \underline{P}_{i}
$$

Accordingly, the marginal costs for the home firm (and similar for the foreign firm) are given by

$$
\begin{aligned}
& \underline{P}_{i} \text { in the home market } \\
& \underline{P}_{i}\left(1+z_{i}\right) \text { in the foreign market }
\end{aligned}
$$

\footnotetext{
${ }^{18}$ Assuming a right-to-manage structure where the employment decision is made after the wage bargaining, this would not be the case. Then, we would have a two-stage discontinuous Bertrand game, first stage in wages and second stage in prices given the wages. This is quite cumbersome as the wage cannot be differentiated across product markets. See e.g. appendix B in the extended working paper version (Andersen and Sørensen (2006b)) for the derivation of a similar wage equation under a right-to-manage structure with the alternative timing sequence under the simplifying assumptions of monopoly unions (unilaterally setting the wages) and perfect competition in the product markets.

${ }^{19}$ Alternatively, this may be justified by either labour market laws, union agreements or by a repeated game argument.
} 
Since prices are determined in Bertrand competition, the firm with the lowest marginal costs including trade frictions supplies a given market. Let $a_{i} \equiv \frac{A_{i}}{A_{i}^{*}}$ define the relative productivity between domestic and foreign firms (comparative advantage) and use that $W=W^{*}$, then the direction of trade is given by ${ }^{20}$

\begin{tabular}{|l|l|}
\hline Trade position & $a_{i}$ \\
\hline Import & $a_{i}<\left(1+z_{i}\right)^{-1}$ \\
\hline Non-traded & $\left(1+z_{i}\right)^{-1} \leq a_{i} \leq 1+z_{i}$ \\
\hline Export & $a_{i}>1+z_{i}$ \\
\hline
\end{tabular}

Lower trade frictions imply both an export possibility and an import threat. The export possibility arises for firms with relatively high productivity who become exporters, i.e. it becomes profitable to penetrate into the foreign market. The import threat arises for less productive non-tradeable firms being driven out of the market by foreign firms. It is an implication that the average productivity across operating firms increases when trade frictions fall. These implications of the model fit empirical evidence quite well (see e.g. Bernard, Jensen and Schott (2003)).

Pricing decisions are influenced by both the presence of trade frictions and the differences in productivity. As in the standard Bertrand game with constant returns to scale and perfect substitutes, the firm with the lowest marginal cost in a given market sets a price equal to the minimum of the monopoly price and the cost of the other firm. The monopoly prices (for the home firm) are

$$
\begin{aligned}
& m \underline{P}_{i} \text { in the home market } \\
& m \underline{P}_{i}\left(1+z_{i}\right) \text { in the foreign market }
\end{aligned}
$$

where $m$ is the monopoly mark-up ratio defined as $m \equiv \frac{\epsilon}{\epsilon-1}>1$. Note that the presence of the trade friction implies price differentiation between the home and foreign markets.

The consumers in the home country face the following prices for the goods in the consumption bundle (for proof see appendix $A$ )

$$
P_{i}=\left\{\begin{array}{ccc}
m \frac{W\left(1+z_{i}\right)}{A_{i}^{*}} & \text { if } & a_{i}<\left(1+z_{i}\right)^{-1} m^{-1} \\
\frac{W}{A_{i}} & \text { if } & \left(1+z_{i}\right)^{-1} m^{-1} \leq a_{i} \leq\left(1+z_{i}\right)^{-1} \\
\frac{\left(1+z_{i}\right) W}{A_{i}^{*}} & \text { if } & \left(1+z_{i}\right)^{-1} \leq a_{i} \leq m\left(1+z_{i}\right)^{-1} \\
m \frac{W}{A_{i}} & \text { if } & a_{i}>m\left(1+z_{i}\right)^{-1}
\end{array}\right.
$$

A change in trade frictions will thus both affect prices directly and indirectly (for given $W$ ). The indirect effects arise because the trade position of commodities may change (non-tradeables affected by the possibility of import or export).

\footnotetext{
${ }^{20}$ For simplicity, it is assumed that if the marginal cost of supplying a market is identical for the firms, then only the domestic firm supplies the market.
} 


\subsection{Wages}

It follows straightforwardly from (3), (5), (8) and (13) that the wage is ${ }^{21}$ (for proof, see Appendix A)

$$
W_{i}=\left\{\begin{array}{ccc}
\left(\alpha\left(1+z_{i}\right) a_{i}+1-\alpha\right) W & \text { if } & \frac{1}{1+z_{i}} \leq a_{i} \leq 1+z_{i} \\
\left(\alpha a_{i} \frac{\left(1+z_{i}\right)^{1-\epsilon}+1}{\left(1+z_{i}\right)^{-\epsilon}+\left(1+z_{i}\right)}+1-\alpha\right) W & \text { if } & 1+z_{i}<a_{i} \leq \frac{m}{1+z_{i}} \\
\left(\alpha a_{i} \frac{a_{i}^{\epsilon-1} m^{1-\epsilon}+1}{m^{-\epsilon} a_{i}^{\epsilon}+\left(1+z_{i}\right)}+1-\alpha\right) W & \text { if } & \frac{m}{1+z_{i}}<a_{i} \leq m\left(1+z_{i}\right) \\
(\alpha m+1-\alpha) W & \text { if } & a_{i}>m\left(1+z_{i}\right)
\end{array}\right.
$$

The easiest way of interpreting the wage schedule linking the wage to trade frictions, (relative) productivity, and thus the trade position of the firm is by considering Figure 1 (for further details and interpretation, see Andersen and Sørensen $(2006 \mathrm{a}))^{22}$. Consider first the bold line giving the relation between the wage and (relative) productivity for a given trade friction. It has two segments, the first where the firm only supplies the domestic market (non-tradeables) and the second where the firm exports. In both segments, the relation is upward sloping for the basic reason that higher productivity increases profitability and therefore, via the sharing rule (8), also the wage. At the productivity level where the firm becomes able to export, the wage curve has a discrete downward jump ${ }^{23}$. The reason for this is that price and thus revenue per worker in the export market is lower than in the domestic market. Hence, incumbent individual workers may be worse off when a firm shifts from being a non-tradeable to an exportable. However, for the firm as well as for the group of workers (including new hirings), the situation is better since profits and employment increase.

\footnotetext{
${ }^{21}$ Note that it is here implicitly assumed that $z_{i} \leq \sqrt{m}-1 \equiv \tilde{z}_{i}$, that is, the relative productivity needed to be able to export is below the relative productivity needed to be able to charge the monopoly price in the home market. Hence, trade frictions are assumed to be small relative to the monopoly markup. We do not impose this restriction in the numerical analysis (see below).

${ }^{22}$ If trade frictions are identical across goods, Figure 1 shows wages across firms for two levels of trade frictions.

${ }^{23}$ Although the wage drop might seem controversial and appear to rely on specific assumptions, one would obtain a similar wage drop in a right-to-manage model with perfect competition on the good markets. Furthermore, such a wage drop is found in reciprocal dumping models, see e.g. Naylor (2000).
} 




Figure 1: Wage schedule. The thick graph is the one with higher trade frictions.

Consider next the effects of a fall in trade frictions of the particular good shifting the wage relation to the thin line in Figure 1. A non-tradeable firm either remains a non-tradeable, becomes an exporter or is squeezed out of business because the foreign firm becomes able to penetrate into the domestic market. If the firm remains a non-tradeable, the wage drops reflecting that protection rents accruing from being shielded from international competition fall. If the firm enters the export market, the wage drops as protection rents fall and further because revenue per employee is lower in the export market (cf. above). For incumbent exporters, the wage increases since the firm is already in the international product market and they benefit from lower trade frictions, and this leaves room for an increase in the wage rate, i.e. there is an increase in specialization rents. Thus, the effect on wages of a fall in trade frictions depends crucially on the competitive position of the firm.

In the process of product market integration, trade frictions fall for many goods. The general equilibrium effects (see below) raise the competitive wage $(W)$ shifting up the wage schedule for all firms.

\section{General Equilibrium Effects}

We can now turn to an analysis of both the aggregate and distributional effects of product market integration. However, due to the complications arising from the general equilibrium effects, few analytical results can be attained, and we therefore present results based on a simulation of the model $^{24}$.

${ }^{24}$ See how to solve the model in Appendix B. 


\section{Parameter choices}

To this end, a number of parameters have to be fixed. The elasticity of substitution between goods is usually set in the range from 2 to 3 (Yi (2003)), and $\epsilon=2.5$ is therefore chosen ${ }^{25}$. The bargaining power of the firms is assumed to equal that of the workers, i.e. $\alpha=\frac{1}{2} \cdot{ }^{26}$ The income share spent on globalized goods $\lambda$ is set to 0.6 . Further, we assume that trade frictions are identical across goods, i.e. that $z_{i}=z$ for all $i$.

Assumptions concerning productivity are crucial for the analysis. Note that we need the distribution of productivity of potential production activities rather than the distribution across actual production only (which we know theoretically is biased due to endogenous determination of production and trade positions). Specifically, the distribution of productivity is assumed to be lognormal, i.e.

$$
\left(\begin{array}{c}
\log A_{i} \\
\log A_{i}^{*}
\end{array}\right) \sim N\left[\left(\begin{array}{c}
\mu \\
\mu
\end{array}\right),\left(\begin{array}{ll}
\sigma^{2} & \sigma_{12} \\
\sigma_{12} & \sigma^{2}
\end{array}\right)\right]
$$

and accordingly, relative productivity is also lognormally distributed

$$
\log a_{i} \sim N\left[0,2(1-\rho) \sigma^{2}\right]
$$

where $\rho=\sigma_{12} / \sigma^{2}$. Throughout, we keep the mean and standard deviation of the productivity fixed such that $E\left(A_{i}\right)=1$ and $\sigma_{A_{i}}=0.75$. Hence, different values of the dispersion of the relative productivities are obtained by changing the correlation $(\rho)$ between productivities in the two countries. We present results for two cases: i) high correlation in productivities (implying a low dispersion of relative productivities) across countries capturing a case of very similar countries, and ii) a low correlation in productivities (implying a high dispersion of relative productivities) across countries capturing a case of less similar countries. Specifically, the high correlation case has $\rho=0.85$, and the low correlation case has $\rho=0.5$. Figure 2 displays the density function for relative productivities in the two cases. The high correlation case (thin line) has relative productivities much more concentrated than the low correlation case (bold line).

We interpret international integration as a process reducing trade frictions $(z)$. Rather than presenting the results as a function of the trade frictions, we use the trade share as a more interpretable measure of openness. This is straightforward as the trade share is monotonously decreasing in the trade friction. Note that the model has no public sector, and hence the trade measure is for the private sector. We report results for a variation in the trade share or openness $^{27}$ from $15 \%$ to $60 \%$ in the high correlation case and from $30 \%$ to $60 \%$ in the low correlation case. This corresponds to a decrease of the trade friction

\footnotetext{
${ }^{25} \mathrm{In} \mathrm{Yi}(2003)$, the elasticity of substitution is between inputs in a production function, cf. above.

${ }^{26}$ The wage share is about $90 \%$ in all the cases considered. Note that the model does not have real capital, and the capital share is a pure profit.

${ }^{27}$ Note that the level of openness associated with a given level of $z$ depends on the distribution for relative productivity.
} 
$z$ from 0.5 to 0 . Note that an aggregate openness of $60 \%$ corresponds to full integration of the $G$ segment $(z=0) .^{28}$

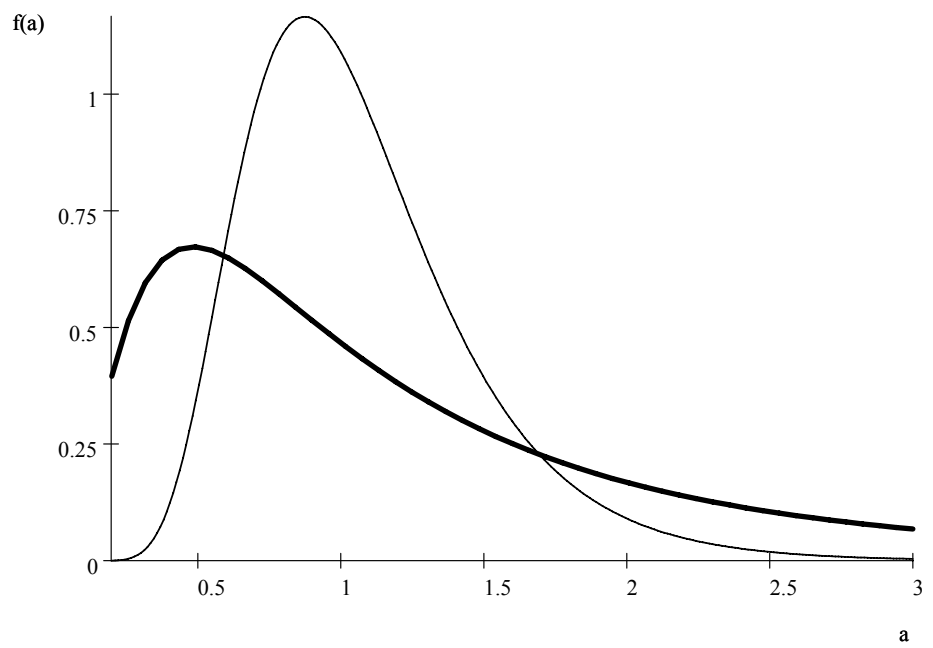

Figure 2: Density function for relative productivity - high and low correlation

When we report the effects of product market integration, we will, among others, include the following variables. Average real wages ${ }^{29}$ given as

$$
\frac{\bar{W}}{Q} \equiv \int_{0}^{1} \frac{W_{i}}{Q} L_{i} d i+\frac{W}{Q} L_{H}
$$

and as measures of inequality, we use the coefficient of variation, which is the standard deviation of real wages divided by the average real wage, i.e.

$$
\frac{\sigma_{W}}{\frac{\bar{W}}{Q}}=\frac{\sqrt{\int_{0}^{1} L_{i}\left(\frac{W_{i}-\bar{W}}{Q}\right)^{2} d i+L_{H}\left(\frac{W-\bar{W}}{Q}\right)^{2}}}{\frac{\bar{W}}{Q}}
$$

The advantage of this measure is that it is invariant to a proportional change in all wages. ${ }^{30}$ Note that in the present setting there is no distinction between

\footnotetext{
${ }^{28}$ An openness measure of $60 \%$ at full integration seems quite low. However, the effects of product market integration propagate and thus increase the level of the openness measure (and the slope of it as a function of product market integration) if the production structure is expanded vertically and we allow for trade in intermediaries (see e.g. Yi (2003)). In fact, this would also increase the aggregate gains from product market integration, which according to the predictions of the model are quite small (see figure 3 and 4), without changing the central predictions about wage inequality.

${ }^{29}$ Note that the average real wage equals aggregate real wages as aggregate employment always equals one.

${ }^{30}$ Using the standard measures (variance and standard deviation) implies that a proportional
} 
the wage rate and wage income, and the two terms are therefore used interchangeably. We also report the elasticity of employment in the $G$ segment with respect to openness, and we decompose it into the following measures of gross job creation and destruction in the $G$ segment $^{31}$

$$
\begin{aligned}
\text { Job creation } & =\frac{\frac{\int_{0}^{1} I_{\left(\Delta L_{i}>0\right)} \Delta L_{i} d i}{L_{G}}}{\frac{\int_{0}^{\frac{\Delta \text { openness }}{\text { openness }}}}{I_{\left(\Delta L_{i}<0\right)}\left|\Delta L_{i}\right| d i}} \\
\text { Job destruction } & =\frac{\frac{L_{G}}{\frac{\Delta \text { openness }}{\text { openness }}}}{}
\end{aligned}
$$

where $I_{()}$is the indicator function.

\section{High correlation of productivities}

Consider first the case of a relatively high correlation $(=0.85)$ in productivity across the two countries and accordingly a relatively low dispersion of relative productivities. The economies are thus fairly similar, which implies that the gains from specialization accruing from further integration are relatively small. However, integration also affects competition via easier market access, and therefore this case can be interpreted as primarily clarifying the role of protection rents rather than specialization rents.

In Figure 3, we plot the following key variables: GDP, total employment in $G$ firms, aggregate wages, average wage in the $G$ segment, the competitive wage, the average wage premium (average wages in the $G$ segment relative to the wage in the $H$ segment), wage dispersion and job creation/destruction as functions of openness (trade share). It is seen that increased openness leads to aggregate gains in terms of increasing GDP. The relative importance of the $G$ segment increases, i.e. a larger fraction of workers are employed in the $G$ segment which also indicates the sectoral reallocation following tighter product

increase in all wages increases the inequality measure. One could argue that such an effect is undesirable as inequality is normally considered to be about the distribution of relative and not absolute wages. In the simulations, there is in fact an underlying increase in the wage level. The standard measures will therefore tend to overstate changes in inequality due to international integration.

${ }^{31}$ Note that for a given trade friction the model determines a given stationary equilibrium, i.e. there is no job reallocations in steady state. Job reallocations are generated by changes in trade frictions by changing the stationary equilibrium. Therefore, the metric has to be related to changes in trade frictions (openness). 
market integration. ${ }^{32}$ The competitive wage is increasing. ${ }^{33}$ Hence, even though workers in the $H$ sector are not directly affected by international integration, they gain. Although international competition becomes more fierce and thus the average mark up/rent decreases, the average wage in the $G$ segment increases due to an increase in the competitive wage (affecting the wage bargaining, cf. above). ${ }^{34}$ The increase in aggregate wages follows straightforwardly, and it is also an immediate implication that average utility increases in the economy.

Turning to the distributional consequences, Figure 3 also shows wage inequality across $G$ firms and for the entire economy as a function of openness. It is seen that wage inequality for the entire economy is decreasing in openness up to a point from which there is a slight increase in wage inequality, i.e. it has a $U$-shape with a strong "left leg". The reason for this is a combination of several factors. First, the average mark-up on the wage in the $H$-sector decreases when product markets become more closely integrated. Second, across $G$ firms wage inequality is $U$-shaped in openness, first falling and then increasing. This $U$-shape is generated by two counteracting effects. Integration lowers protection-rents in non-tradeable firms shielded from international competition, while it increases specialization rents arising from better matching production to productivities (specialization), cf. Section 2.6. Hence, at first an increase in openness reduces pay differences generated by rents which can be appropriated when protected from international competition, and subsequent wage inequality tends to increase since wages come to follow (relative) productivity more closely. However, since there is low dispersion in relative productivities, the specialization effect does not carry much weight, and therefore the $U$-shape almost disappears at the aggregate level.

In the $G$ segment, many jobs are created and destructed in the process of product market integration. Job creation is above job destruction reflecting the increasing employment level and thus job relocation from the $H$ to the $G$ sector $^{35}$. Gross job flows are rather large compared to net job creation. This points out that substantial job reallocation can be associated with the effects of international integration. Although gross job-turnover increases with openness, it is the case that net job-creation diminishes with openness. At low levels of openness, large net job creation is achieved with little job reallocation, and vice versa at a high level of openness. Finally, note that international integration cannot in itself account for a constant level of job destruction and creation. The

\footnotetext{
${ }^{32}$ Due to the Cobb-Douglas preferences, the elasticity of substitution of goods from the two segments equals one, and thus a fixed share $(\lambda)$ of income is spent on goods from the $\mathrm{G}$ segment. However, if the elasticity of substitution was above (below) one, the fraction of income used on goods from the $\mathrm{G}$ segment would be increasing (decreasing), and the net job creation in the $G$ segment would be higher (lower), as would the aggregate gains from integration.

${ }^{33}$ This result can also be shown analytically.

${ }^{34}$ For sufficiently small values of $\lambda$ this is not the case. The reason is that the aggregate gains from trade, and thus the competitive wage, are positively related to the size of the $G$ segment $(\lambda)$. This means that for low values of $\lambda$, the effect of a lower average mark up dominates. However, aggregate wages always increase.

${ }^{35}$ This can loosely be interpreted as an endogenous skill-bias in labour demand shifting employment from low to high productivity activities.
} 
reason is that the job flows are released as a response to structural changes induced by a change in trade friction. Hence, continuous shifts in trade frictions are needed if this mechanism shall generate an ongoing process of job flows, and this is naturally bounded by the limiting case of perfect integration (zero trade frictions). Hence, integration can in this sense be a temporary, but not a permanent, source of job destruction and creation.
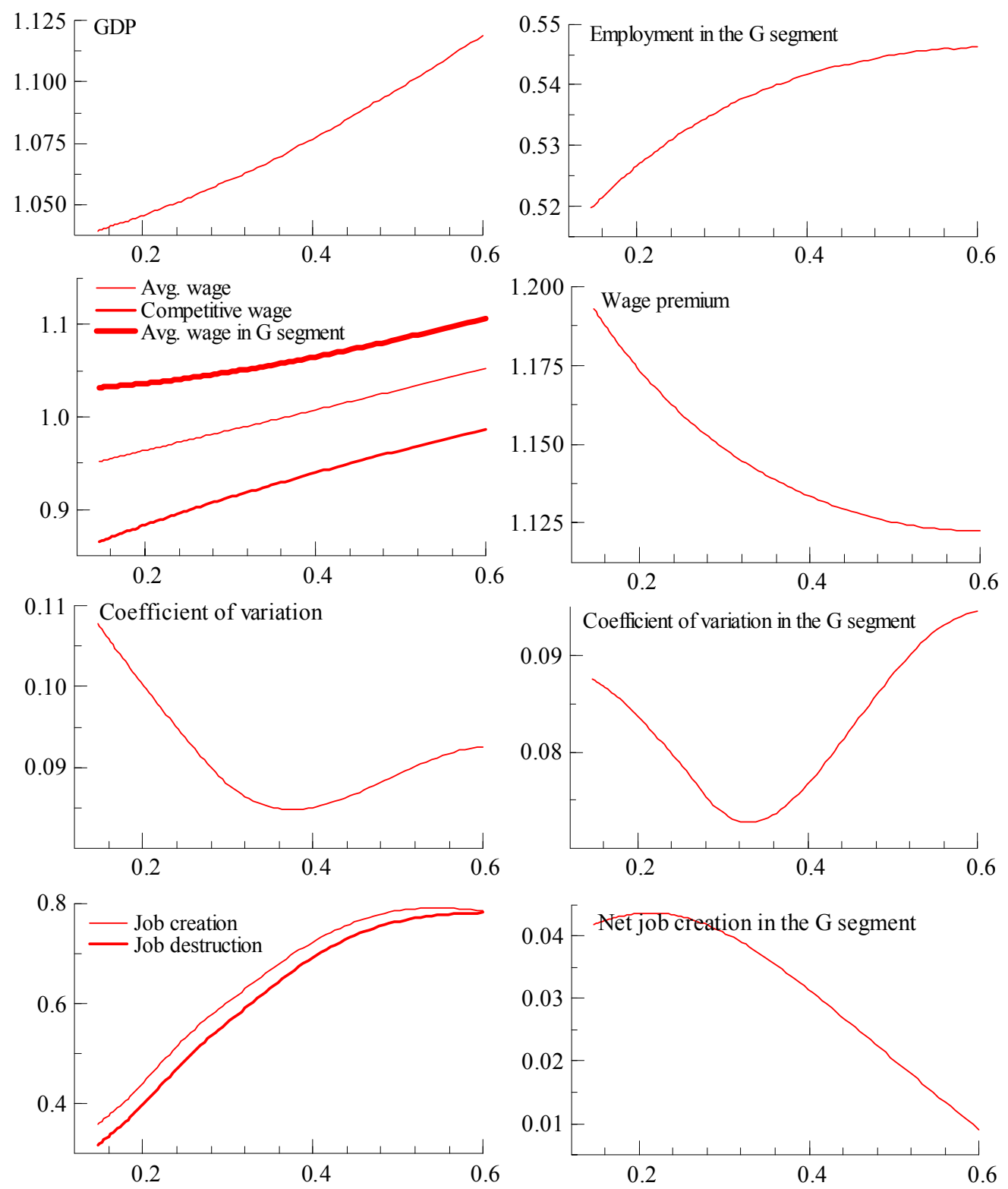

Figure 3: Key variables plotted against openness - high correlation case 


\section{Low correlation of productivities}

The case with a low correlation $(=0.5)$ in productivities across the two countries implies that there is more dispersion in relative productivities. Accordingly, the specialization effect may play a larger role here. The results for this case are reported in Figure 4.

The aggregate trends are the same as in the high correlation case, that is, increasing GDP, employment in $G$ firms, the competitive wage and average wages capturing the gains from international integration. Actually, the gains are larger in this case since the gains from specialization which can be reaped from further integration are larger when relative productivity is more dispersed across countries.

An important difference to the low dispersion case arises when considering wage inequality. It is seen from Figure 4 that wage inequality at first falls slightly, and then increases - again a $U$-shape, but in this case with a strong "right leg". The reason for this is partly that the average wage premium falls by less than in the high correlation case and partly a stronger and monotone increase in wage inequality across $G$ firms driven by a larger role of specialization rents (due to high dispersion of relative productivities). With tighter integration, wages follow (relative) productivities more closely, and since there is much more variation in relative productivities, it follows that wage inequality grows. Gross job creation in the $G$ segment is in this case also far above the net job creation in the $G$ segment stressing the importance of intrasegmental reallocation of jobs in the integration process. However, the gross creation and destruction measures are hump-shaped and not monotonically increasing in this case. 

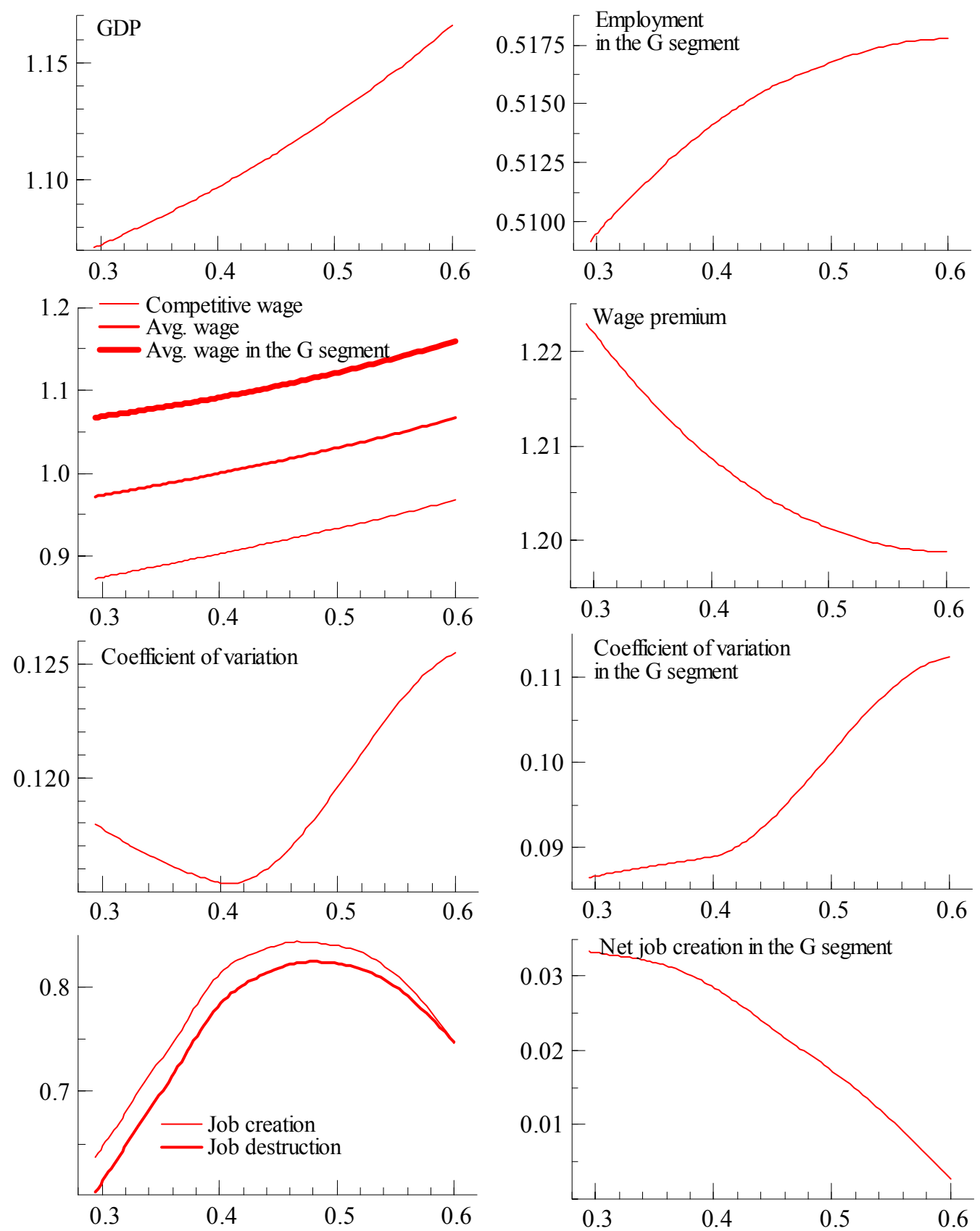

Figure 4: Key variables plotted against openness - low correlation case 


\section{Integration and the efficiency-equity trade-off}

The main findings can be summarized by means of Figure 5 showing the different positions in the efficiency-equity space for the economy depending on the level of openness. Efficiency is here measured by the mean income and equity by the standard deviation of income ${ }^{36}$. Note that utility is proportional to income in the present framework. Lowering of trade frictions causes a movement from the "bottom" to the "top" of the curve. That is, first integration entails gains in both the efficiency and equity dimension, but at a certain level of integration a trade-off arises in the sense that further efficiency gains are achieved at the costs of rising inequality ${ }^{37}$. Hence, product market integration does not necessarily cause a worsening of the equity-efficiency trade-off. However, for a sufficiently open economy a trade-off arises suggesting that political preferences over efficiency and equity imply an optimal level of integration. Comparison of the high and low correlation cases shows that more equity is gained for given improvements in efficiency at low levels of integration if the integrating economies are fairly similar (high correlation case). Comparison of the two cases also reveals a difference in the position in the efficiency-equity space where the locus in the low correlation case is to the north-east of the locus in the high correlation case. This indicates that if integration takes place between two countries being more different (in the sense of a lower correlation in productivities), then both expected income and inequality would be higher than if the integrating economies were more similar. This suggests that distributional issues are more likely to arise for integration among less similar than more similar countries.

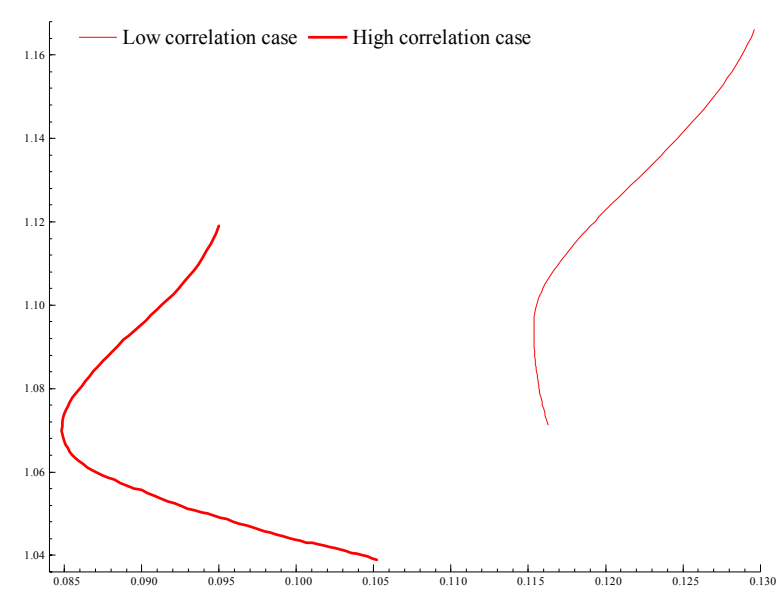

Figure 5: The efficiency-equity trade-off

\footnotetext{
${ }^{36}$ Note the income measure is the sum of wage and profit income. Profit income is assumed to be distributed equally among all households, and hence the distributional dimension only refers to wage income.

${ }^{37}$ The turning point where gains in both dimensions turn into a trade-off arises here for an openness measure of $35-40 \%$. Note that this corresponds to different levels of trade frictions since openness varies from $15 \%$ to $60 \%$ in the high correlation case, and $30 \%$ to $60 \%$ in the low correlation case.
} 


\section{Extensions}

The preceding analysis has assumed the two countries to share the same aggregate properties in order to focus on the role of market penetration, specialization and rents. While this assumption to a first approximation may be a reasonable assumption in an analysis of e.g. European integration, it is important to assess the extent to which the results are robust to the presence of aggregate asymmetries. Considering asymmetries arising from differences in size, average productivity and the relative size of the $H$-sector to the $G$-sector, it was found (results not shown) that the qualitative results are the same, and it is particularly important to stress that the effects on inequality reported above are qualitatively similar.

In the numerical analysis, we have imposed the simplifying assumption that trade frictions are identical across goods. However, we have also simulated the model without this restriction. ${ }^{38}$ The qualitative results of these simulations (not shown) are similar to those reported above.

While the robustness checks are not exhaustive, they do suggest that the results are not crucially dependent on aggregate symmetry and homogenous trade frictions.

\section{Conclusion and extensions}

This paper has taken a first step in considering both the aggregate and disaggregate consequences of international integration in a framework allowing for an endogenous determination of specialization and trade flows across countries as well as imperfect competition in both product and labour markets. The focus has been on further product market integration and the effects this may have on labour markets.

It has been shown that the relation between product market integration and inequality is complex. This paper has stressed two such reasons. One is that the wage in the $H$-sector is affected (due to gains from trade) implying that even groups shielded from integration may gain from more integration. This changes the relative wage between the $H$-sector and the $G$-sector. The other reason is that the relation between wage inequality and openness within the $G$-sector may be either $U$-shaped or increasing in openness. The reason for this ambiguity is that two major effects are at stake. First, workers in non-tradeable firms face lower "protection rents" as markets integrate and the threat of market penetration of foreign firms becomes stronger. Second, workers in exporting firms gain a larger "specialization rent" alongside market integration lowering frictions in trade. The net-effect of these counter-acting effects is that aggregate wage inequality tends to be $U$-shaped.

This non-linear relation suggests that it is not possible to make unambiguous statements concerning how openness affects inequality. However, it implies that when international integration or openness reaches a sufficiently high level,

\footnotetext{
${ }^{38}$ We have considered cases where trade frictions are log-normally or uniformly distributed. Trade frictions are in all cases assumed to be independent of productivities.
} 
higher wage inequality is inevitable, irrespective of whether countries are very similar or not. The finding of a non-linear relation is also interesting from an empirical perspective. Both since there is evidence for some countries that inequality follows a U-path (see e.g. Atkinson (2003) and Alderson and Nielsen $(2002))^{39}$, and since it points to the danger of using a "linear" approach when trying to explain the development in inequality.

It is a further implication that international integration through structural changes affects job creation and job destruction. Gross levels of job reallocation are high relative to net job creation. Thus, most of the reallocation takes place within the sector directly affected by globalization.

The consequences of globalization for inequality are a major concern. It has been shown that a trade-off between efficiency and equity does not arise when integration proceeds from a low level of openness, but at higher levels of openness a trade-off between efficiency and equity arises. Moreover, in comparing integration between more similar and less similar countries, it is the case that the trade-off in the latter case offers a higher mean income, but also more inequality.

While illustrative, the present model rests on a number of simplifying assumptions which it would be necessary to generalize before proceeding to a genuine empirical assessment of the model. In particular, it would be interesting to introduce a richer labour market formulation allowing different types of labour as well as an endogenous determination of skills (education). This would allow us to analyze what happens to inequality both between different and identical types of labour, and the short- and long run consequences of international integration for inequality. It would also be interesting to analyse whether the predictions are robust to changes in the type of strategic interaction between firms, i.e. are the results robust to Cournot competition and Bertrand competition with differentiated products?

In future work, it would in particular be important to consider the role of unemployment and the public sector. The present model has full employment implying that aggregate gains from integration and the implied increase in income lead to an increasing wage level (the dominant effect running via the H-sector), whereas in the presence of unemployment a larger share of the effect may show up in the employment level. This is important for the distributional consequences.

An important further step in addressing these issues would be to introduce the public sector explicitly in the analysis. Not least because this sector also should be considered as a "home sector". Distributional concerns are a strong motivating factor behind many public sector schemes, and it is therefore of

\footnotetext{
${ }^{39}$ It is difficult to infer anything on the role of international integration for inequality since it is also affected by other factors such as unionization, skill distribution, non-labour income and welfare policies. Hence, changes in inequality measures do not only arise from changes in labour market income, and this makes it very hard to draw precise conclusions. Moreover, part of the increase in labour earnings inequality from the mid 1980s to the mid 1990s can be explained by changes in employment and working hours since full-time labour earnings stayed rather constant (Williamson (2002)).
} 
importance to analyse how both the need and scope for such schemes are affected by integration. This is needed to address the very important question whether the need for welfare state arrangements becomes stronger with further integration and in what way the scope for such policies is affected. 


\section{References}

[1] Alderson, A.S. and F. Nielsen, 2002, "Globalization and the Great U-turn: Income Inequality Trends in 16 OECD Countries", American Journal of Sociology, 107, 1244-1299

[2] Andersen, T.M. and A. Sørensen, 2006a, "International Product Market Integration, Rents and Wage Formation", Working Paper, University of Aarhus (revised version of CEPR Discussion Paper 3995).

[3] Andersen, T.M. and A. Sørensen, 2006b, "Labour market effects of product market integration - aggregate and distributional effects", Working Paper, University of Aarhus

[4] Atkinson, A.B., 2003, "Income Inequality in OECD Countries: Data and Explanations", CESifo Economic Studies, Vol. 49, 4/2003, 479-513

[5] Atkinson, A.B., 2006, "The Economics of the Welfare State in Today's World", unpublished working paper

[6] Autor, D.H., L.F. Katz and M.S. Kearney, 2006, "The Polarization of the U.S. Labour Market, NBER, Working Paper 11986

[7] Baldwin, R., 2006, "Globalisation: The great unbundling", Working Paper.

[8] Bernard, A.B., J. Bradford Jensen and P.K. Schott, 2003, "Falling trade Costs, Heterogeneous Firms, and Industry Dynamics", 2003, NBER Working Paper 9639.

[9] Bernard, A.B., J. Eaton, J. Bradford Jensen and S. Kortum, 2003, "Plants and productivity in international trade", American Economic Review, 93, 1268-1290.

[10] Bernard, A.B., and J. Bradford Jensen, 1999, "Exceptional exporter performance: cause, effect or both?", Journal of International Economics, 47, $1-25$

[11] Bernard, A.B., and J. Bradford Jensen, 2001, "Exporting and productivity: The importance of Reallocation", Working Paper, Center for Economic Studies, U.S. Census Bureau

[12] Blinder, A., 2005, "Fear of Offshoring", Working Paper University of Princeton

[13] Boulhol, H. S. Dobbelaere, S. Maioli (2006), "Imports as product and labour market discipline", IZA working paper 2178

[14] Brander, J., 1981, "Intra-industry trade in identical commodities", Journal of International Economics, 11, 1-14. 
[15] Davis, D.R. and D.E. Weinstein, 2002, "An Account of Global Factor Trade", American Economic Review 92, 1423-1453.

[16] Dornbusch, R., S. Fischer and P.A. Samuelson, 1977, "Comparative Advantage, Trade and Payments in a Ricardian Model with a Continuum of Goods", American Economic Review, 67, 823-839.

[17] Grossman, G.M., and E. Rossi-Hansberg, 2006a, "Trading Tasks: A Simple Theory of Offshoring", Working paper

[18] Grossman, G.M., and E. Rossi-Hansberg, 2006b, "The Rise of Offshoring: It's Not Wine for Cloth Anymore", Working paper.

[19] Gürtzen, N., 2002, "Trade liberalization and union wages in a differentiated Bertrand Oligopoly", Open Economics Review, 13, 133-151.

[20] Jean, S. and G. Nicoletti, 2002, "Product Market Integration and Wage Premia in Europa and North America: An Empirical Investigation, Working Paper 318, Economics Department, OECD

[21] Lemieux, T., 2005, "Increasing Residual Wage Inequality: Composition Effects, Noisy Data, or Rising Demand for Skill", Working Paper

[22] Melitz, M. J., 2003, "The Impact of Trade on Intra-Industry Reallocations and Aggregate Industry Productivity", Econometrica, 71, 1695-1725.

[23] Midelfart-Knarvik, K.H., H. G. Overman, S.J. Redding and A.J. Venables, 2000, "The Location of European Industry", Economic Papers 142, European Commission, Directorate-General for Economic and Financial Affairs.

[24] Moene, K.O. and M. Wallerstein, 1993, "Bargaining Structure and Economic Performance", in R. J. Flanagan, K.O. Moene and M. Wallerstein, Trade Union Behaviour, Pay Bargaining and Economic Performance, Clarendon Press, Oxford.

[25] Naylor, R., 2000, "Trade and Wages When the Trade Regime is Determined Endogenously", Review of International Economics, vol. 8 (3), 556-565.

[26] Nicoletti, G., A. Bassanini, E. Ernst, S. Jean, P. Santiago and P. Swaim, 2001, "Product and Labour Market Interactions in OECD Countries, Working Paper 312, Economics Department, OECD

[27] Revenga, A.L., 1992, "Exporting Jobs? - The Impact of Import Competition on Employment and Wages in U.S. Manufacturing", Quarterly Journal of Economics, 107, 255-84

[28] Schank, T., C. Schnabel and J. Wagner, 2004, "Exporting Firms Do Not Pay Higher Wages - Ceteris Paribus. First Evidence from Linked EmployerEmployee Data", IZA, Working Paper 1185 
[29] Williamson, J.G., 2002, "Winners and Losers Over Two Centuries of Globalization", NBER Working Paper 9161.

[30] Yi, K.-M., 2003, "Can Vertical Specialization Explain the Growth of World Trade?", Journal of Political Economy, 111, 52-102. 


\section{Appendix A}

\section{Determining prices}

From the standard Bertrand game with perfect substitutes and constant marginal costs, we know that the firm with the lowest marginal costs supplies the market. Since the reservation wage is identical in the two countries, differences in marginal costs depend on trade frictions and differences in productivity. The marginal cost of the home firm in the home market is given by

$$
M C_{\text {home market }}=\frac{W}{A_{i j}}
$$

and for the foreign firm in the home market

$$
M C_{\text {home market }}^{*}=\frac{W}{A_{i j}^{*}}\left(1+z_{i j}\right)
$$

and accordingly the home firm supplies the home market if

$$
M C_{\text {home market }} \leq M C_{\text {home market }}^{*} \Leftrightarrow a_{i j} \geq\left(1+z_{i j}\right)^{-1}
$$

and the foreign firm supplies the home market if

$$
a_{i j}<\left(1+z_{i j}\right)^{-1}
$$

where

$$
a_{i j}=\frac{A_{i j}}{A_{i j}^{*}}
$$

denotes relative productivity (comparative advantage). From the standard Bertrand game, we also know that the firm supplying the market sets the price equal to the smallest of the marginal costs of the other firm and the monopoly price. The monopoly prices for the home firm and foreign firm are given by (note that the consumer price index is normalized to one)

$$
\begin{gathered}
\left(P_{i j}^{*}\right)_{\text {home market }}^{\text {monopoly }}=\arg \max _{P_{i j}}\left(P_{i j}-\frac{W}{A_{i j}}\right) P_{i j}^{-\epsilon} \lambda I P_{C}^{\epsilon-1}=\frac{\epsilon}{\epsilon-1} \frac{W}{A_{i j}}=m \frac{W}{A_{i j}} \\
\left(P_{i}^{*}\right)_{\text {home market }}^{\text {monopoly }}=\arg \max _{P_{i j}}\left(P_{i j}-\frac{W}{A_{i j}}\left(1+z_{i j}\right)\right) P_{i j}^{-\epsilon} \lambda I P_{C}^{\epsilon-1}=\frac{\epsilon}{\epsilon-1} \frac{W}{A_{i j}^{*}}\left(1+z_{i j}\right)=m \frac{W}{A_{i j}^{*}}
\end{gathered}
$$

Now consider the cases where the home firm supplies the home market, that is $a_{i j} \geq\left(1+z_{i j}\right)^{-1}$ then the price is given by

$$
P_{i j}=\min \left(\frac{W}{A_{i j}^{*}}\left(1+z_{i j}\right), m \frac{W}{A_{i j}}\right)=\left\{\begin{array}{ccc}
m \frac{W}{A_{i j}} & \text { if } & a_{i j}>\frac{m}{1+z_{i j}} \\
\frac{W}{A_{i j}^{*}}\left(1+z_{i j}\right) & \text { if } & a_{i j}<\frac{m}{1+z_{i j}}
\end{array}\right.
$$


Consider now the cases in which the foreign firm supplies the home market, that is $a_{i j}<\left(1+z_{i j}\right)^{-1}$ then the price is given by

$$
P_{i j}=\min \left(\frac{W}{A_{i j}}, m \frac{W}{A_{i j}^{*}}\left(1+z_{i j}\right)\right)=\left\{\begin{array}{ccc}
m \frac{W}{A_{i j}^{*}}\left(1+z_{i j}\right) & \text { if } \quad a_{i j}<\frac{1}{\left(1+z_{i j}\right) m} \\
\frac{W}{A_{i j}^{*}}\left(1+z_{i j}\right) & \text { if } \quad a_{i j}>\frac{1}{\left(1+z_{i j}\right) m}
\end{array}\right.
$$

and hence we have

$$
P_{i j}=\left\{\begin{array}{ccc}
m \frac{W\left(1+z_{i j}\right)}{A_{i j}^{*}} & \text { if } & a_{i j}<\left(1+z_{i j}\right)^{-1} m^{-1} \\
\frac{W}{A_{i j}} & \text { if } & a_{i j} \in\left[\left(1+z_{i j}\right)^{-1} m^{-1},\left(1+z_{i j}\right)^{-1}\right) \\
\frac{\left(1+z_{i j}\right) W}{A_{i j}^{*}} & \text { if } & a_{i j} \in\left[\left(1+z_{i j}\right)^{-1}, m\left(1+z_{i j}\right)^{-1}\right) \\
m \frac{W}{A_{i j}} & \text { if } & a_{i j}>m\left(1+z_{i j}\right)^{-1}
\end{array}\right.
$$

which are the prices in the paper. In exactly the same way, we calculate the prices in the foreign market.

\section{Real wages}

Note from the wage equation we have

$$
W_{i j}=\alpha \frac{R_{i j}}{L_{i j}}+(1-\alpha) W
$$

and hence we need to calculate revenue and employment for each firm. Both can be calculated from the demand functions (note that all aggregate variables are identical in the two markets due to the aggregate symmetry assumption)

$$
\begin{gathered}
C_{i j}^{d}=\lambda I P_{C}^{\epsilon-1} P_{i j}^{-\epsilon} \\
\left(C_{i j}^{d}\right)^{*}=\lambda I P_{C}^{\epsilon-1}\left(P_{i j}^{*}\right)^{-\epsilon}
\end{gathered}
$$

after correction for productivity and prices. Consider home firms and consider first a non-traded good, that is $a_{i j} \in\left[\left(1+z_{i j}\right)^{-1}, 1+z_{i j}\right]$ then

$$
\begin{gathered}
L_{i j}=\lambda I P_{C}^{\epsilon-1} P_{i j}^{-\epsilon} \frac{1}{A_{i j}} \\
R_{i j}=\lambda I P_{C}^{\epsilon-1} P_{i j}^{-\epsilon} P_{i j} \\
W_{i j}=\alpha \frac{P_{i j}^{-\epsilon} \lambda I P_{C}^{\epsilon-1} P_{i j}}{P_{i j}^{-\epsilon} \lambda I P_{C}^{\epsilon-1} \frac{1}{A_{i j}}}+(1-\alpha) W=\alpha A_{i j} P_{i j}+(1-\alpha) W
\end{gathered}
$$

where $P_{i j}$ is determined in the paragraph above. Consider now a home firm exporting

$$
\begin{gathered}
L_{i j}=P_{i j}^{-\epsilon} \lambda I P_{C}^{\epsilon-1} \frac{1}{A_{i j}}+\left(P_{i j}^{*}\right)^{-\epsilon} \lambda I P_{C}^{\epsilon-1} \frac{1+z_{i j}}{A_{i j}} \\
R_{i j}=\lambda I P_{C}^{\epsilon-1} P_{i j}^{-\epsilon} P_{i j}+\lambda I P_{C}^{\epsilon-1}\left(P_{i j}^{*}\right)^{-\epsilon} P_{i j}^{*}
\end{gathered}
$$




$$
W_{i j}=\alpha \frac{P_{i j}^{-\epsilon} P_{i j}+\left(P_{i j}^{*}\right)^{-\epsilon} P_{i j}^{*}}{P_{i j}^{-\epsilon} \frac{1}{A_{i j}}+\left(P_{i j}^{*}\right)^{-\epsilon} \frac{1+z_{i j}}{A_{i j}}}+(1-\alpha) W
$$

where $\left(P_{i j}, P_{i j}^{*}\right)$ is determined in the paragraph above. Inserting prices one obtains

$$
W_{i j}=\left\{\begin{array}{ccc}
\left(\alpha\left(1+z_{i j}\right) a_{i j}+1-\alpha\right) W & \text { if } & \frac{1}{1+z_{i j}} \leq a_{i j} \leq 1+z_{i j} \\
\left(\alpha a_{i j} \frac{\left(1+z_{i j}\right)^{1-\epsilon}+1}{\left(1+z_{i j}\right)^{-\epsilon}+\left(1+z_{i j}\right)}+1-\alpha\right) W & \text { if } & 1+z_{i j}<a_{i j} \leq \frac{m}{1+z_{i j}} \\
\left(\alpha a_{i j} \frac{a_{i j}^{\epsilon-1} m^{1-\epsilon}+1}{m^{-\epsilon} a_{i j}^{\epsilon}+\left(1+z_{i j}\right)}+1-\alpha\right) W & \text { if } & \frac{m}{1+z_{i j}}<a_{i j} \leq m\left(1+z_{i j}\right) \\
(\alpha m+1-\alpha) W & \text { if } & a_{i j}>m\left(1+z_{i j}\right)
\end{array}\right.
$$

if $z_{i j} \leq z_{i j}=\sqrt{m}-1$ and

$$
W_{i j}=\left\{\begin{array}{clc}
\left(\alpha\left(1+z_{i j}\right) a_{i j}+1-\alpha\right) W & \text { if } & \frac{1}{1+z_{i j}} \leq a_{i j} \leq \frac{m}{1+z_{i j}} \\
(\alpha m+1-\alpha) W & \text { if } & \frac{m}{1+z_{i j}}<a_{i j} \leq 1+z_{i j} \\
\left(\alpha a_{i j} \frac{a_{i j}^{\epsilon-1} m^{1-\epsilon}+1}{m^{-\epsilon} a_{i j}^{\epsilon}+\left(1+z_{i j}\right)}+1-\alpha\right) W & \text { if } & 1+z_{i j}<a_{i j} \leq m\left(1+z_{i j}\right) \\
(\alpha m+1-\alpha) W & \text { if } & a_{i j}>m\left(1+z_{i j}\right)
\end{array}\right.
$$

if $z_{i j}>z_{i j}$ (this condition determines whether a firm becomes able to charge the monopoly price in the domestic market before it becomes able to export).

\section{Appendix B}

To solve the model, it is useful to separate aggregate variables from firm specific variables in the $G$ sector. We use the fact that at the aggregate level, sectors and countries are identical in equilibrium and accordingly all aggregate variables are identical. Before solving the model define

$$
w \equiv \frac{W}{Q}
$$

as the real minimum wage. Consider first prices in the $G$ sector and note that we can write

$$
\begin{aligned}
& p_{i j} \equiv w Q \tilde{p}_{i j} \\
& p_{i j}^{*} \equiv w Q \tilde{p}_{i j}^{*}
\end{aligned}
$$

where $\tilde{p}_{i j}=f_{0}\left(A_{i j}, A_{i j}^{*}, \epsilon, z_{i j}\right)$ and $\tilde{p}_{i j}^{*}=f_{0}^{*}\left(A_{i j}, A_{i j}^{*}, \epsilon, z_{i j}\right)$. Accordingly, we can write

$$
\begin{aligned}
P_{G} & =\left(\int_{0}^{1} \int_{0}^{1}\left(w Q \tilde{p}_{i j}\right)^{1-\epsilon} d j d i\right)^{\frac{1}{1-\epsilon}} \\
& =w Q\left(\int_{0}^{1} \int_{0}^{1} \tilde{p}_{i j}^{1-\epsilon} d j d i\right)^{\frac{1}{1-\epsilon}} \\
& \equiv w Q \tilde{P}_{G}
\end{aligned}
$$


and hence the consumer price index is given by

$$
Q=P_{G}^{\lambda} P_{H}^{1-\lambda}=\left(w Q \tilde{P}_{G}\right)^{\lambda}(w Q)^{1-\lambda}=w Q \tilde{P}_{G}^{\lambda}
$$

where $\tilde{P}_{G}=f_{1}\left(\left\{A_{i j}, A_{i j}^{*}, z_{i j}\right\}_{i, j \in[0,1] \times[0,1]}, \epsilon\right)$. In fact, we obtain the real minimum wage from this expression

$$
w=\tilde{P}_{G}^{-\lambda}
$$

Now we do the same for employment

$$
\begin{aligned}
& L_{i j}=\frac{\lambda I}{P_{G}}\left(\frac{p_{i j}}{P_{G}}\right)^{-\epsilon} \tilde{L}_{i j}+\frac{\lambda I}{P_{G}}\left(\frac{p_{i j}^{*}}{P_{G}}\right)^{-\epsilon} \tilde{L}_{i j}^{*} \\
&=\frac{\lambda I}{w Q \tilde{P}_{G}}\left(\frac{w Q \tilde{p}_{i j}}{w Q \tilde{P}_{G}}\right)^{-\epsilon} \tilde{L}_{i j}+\frac{\lambda I}{w Q \tilde{P}_{G}}\left(\frac{w Q \tilde{p}_{i j}^{*}}{w Q \tilde{P}_{G}}\right)^{-\epsilon} \tilde{L}_{i j}^{*} \\
&=\frac{\lambda I}{w Q \tilde{P}_{G}}\left(\frac{\tilde{p}_{i j}}{\tilde{P}_{G}}\right)^{-\epsilon} \tilde{L}_{i j}+\frac{\lambda I}{w Q \tilde{P}_{G}}\left(\frac{\tilde{p}_{i j}^{*}}{\tilde{P}_{G}}\right)^{-\epsilon} \tilde{L}_{i j}^{*} \\
&=\frac{\lambda I}{w Q} \tilde{P}_{G}^{\epsilon-1}\left(\tilde{p}_{i j}^{-\epsilon} \tilde{L}_{i j}+\left(\tilde{p}_{i j}^{*}\right)^{-\epsilon} \tilde{L}_{i j}^{*}\right) \\
& L_{G}=\int_{0}^{1} \int_{0}^{1} L_{i j} d i d j=\frac{\lambda I}{w Q} \tilde{P}_{G}^{\epsilon-1} \int_{0}^{1} \int_{0}^{1}\left(\tilde{p}_{i j}^{-\epsilon} \tilde{L}_{i j}+\left(\tilde{p}_{i j}^{*}\right)^{-\epsilon} \tilde{L}_{i j}^{*}\right) d i d j \equiv \frac{\lambda I}{w Q} \tilde{L}_{G}
\end{aligned}
$$

and note that $\tilde{L}_{G}=f_{2}\left(\left\{A_{i j}, A_{i j}^{*}\right\}_{i, j \in[0,1] \times[0,1]}, \epsilon, z\right)$. From the H-sector we have

$$
L_{H}=Y_{H}
$$

and

$$
Y_{H}=\frac{(1-\lambda) I}{P_{H}}=\frac{(1-\lambda) I}{W}=\frac{(1-\lambda) I}{w Q}
$$

Now we can consider the equilibrium condition on the labour market

$$
L_{H}+L_{G}=1 \Leftrightarrow \frac{(1-\lambda) I}{w Q}+\frac{\lambda I}{w Q} \tilde{L}_{G}=1
$$

which using (15) determines real GDP as

$$
\frac{I}{Q}=\left(1-\lambda+\lambda \tilde{L}_{G}\right)^{-1} \tilde{P}_{G}^{-\lambda}
$$

